into the scope of this paper, it may be briefly remarked that in Freund's case it was most probably syphilitic in origin; in Hutchinson's it was associated with septic endocarditis, and in Bramwell's there was a history of severe cerebral trauma. In my case, however, as in Conway's and others, syphilis could probably be excluded, and there was no arterio-sclerosis or other pathological lesion of the vessels. It is probable that a local congenital weakness of the wall of the artery was the most important factor.

\title{
REFERENCES
}

1. Beadles.-Brain, Vol. XXX, p. 285, 1907.

2. Bramwell.-Edinburgh Med. Jl., Vol. IX, p. 152, 1889.

3. Conway.-Brit. Jl. of Ophthal., Vol. X, p. 78, 1926.

4. Freund.-Klin. Monatsbl. f. Augenheilk., Vol. LVI, p. 468, 1916.

5. Hutchinson.-Trais. Ophthal. Soc., U.K., Vol. IX, p. 152, 1889.

6. Kummell.-Münchener. Med. Wochenschr., Vol. LVIII, p. 1293, 1911.

7. Weir Mitchell. - Jl. of Nervous and Mental Diseases, Vol. XIV, p. 44, 1889.

8. Sosman.-Brit. Jl. of Radiology, Vol. XXX, p. 468, 1925.

9. Stilling.-Zeitschr.f. Ophthal., Vol. III, p. $465,1833$.

\section{A BEND IN THE SIXTH CRANIAL NERVE-AND ITS PROBABLE SIGNIFICANCE}

\author{
E. WolfF \\ LONDON
}

THE weakling of the cranial contents, the sixth nerve may be affected in almost any type of cerebral lesion. It is thus notorious, if involved alone, for having no localizing value.

To quote Uhthoff(1): "Unilateral paralysis of the rectus externus may usually be considered as a pressure or distant symptom in tumour cases especially if incomplete. It often affords no data as to the localization of the process as is shown by the diminution of the paralysis after decompressive operation. It is not justifiable from the unilateral distribution of the paralysis of the external rectus to conclude that the seat of the tumour is on the same hemisphere. I have had cases confirmed by autopsy where the tumour was contralateral."

Many theories have been evolved to account for this.

Collier ${ }^{(2)}$ thought that it was due to a shifting backwards of the brain stem. Those nerves whose direction was most nearly frontocaudal would be involved before the others. Thus the sixth would be first, then the third, and lastly, the seventh and eighth.

But Cushing ${ }^{(3)}$ points out that mere traction or elongation of the nerve does not produce palsy-as is seen especially in cases of cerebello-pontine tumour where the seventh nerve is often stretched to twice its length without resultant facial palsy. 
Also if the above were correct why does the frailer fourth nerve with its longer antero-posterior course escape? The answer usually given is that it is protected by the free margin of the tentorium cerebelli in which it lies for part of its course, an explanation that will hardly hold for an antero-posterior pull.

It is obvious there must be some other factor.

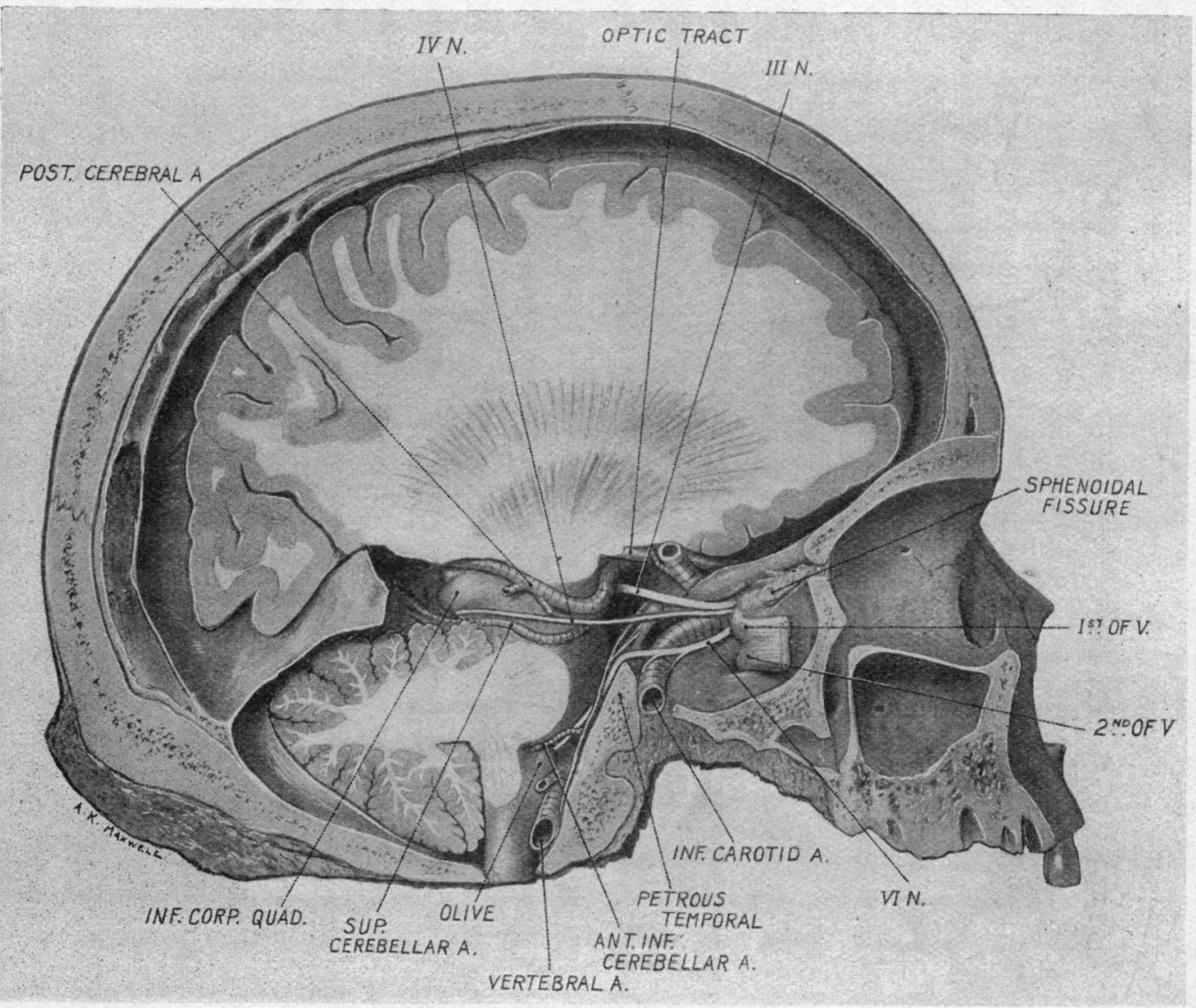

Professor Cushing ${ }^{(3)}$ showed that the antero-inferior cerebellar artery, when it ran ventral to the sixth nerve (a relation present according to Stopford ${ }^{(4)}$ in 86 per cent. on the right side and 81 per cent. on the left) might as a result of increased intracranial pressure press on and groove the nerve and the underlying pons. A similar pressure may be produced by the internal auditory artery.

Now, doubtless in some cases this may result in palsy of the nerve. But the arteries are normally small soft structures and they press the nerve into the softish brain substance. Hence the 
grooving of the nerve and the pons does not necessarily mean a palsy of the abducens.

One somehow feels that the structure producing the pressure must be of a firmer consistency.

It is my endeavour in this note to show that such a structure exists. The sixth nerve is usually regarded as having a long straight antero-posterior course. This fallacy, I think, arises from the fact that the brain is usually removed before the whole course of the nerve is studied.

Now the abducens emerges from the brain between the pons and the lateral part of the pyramid. It is attached to the pons for a few millimetres then runs upwards, forwards, and slightly outwards between the pons and the occipital bone to pierce the dura below and to the inner side of the fifth.

Under the dura it runs almost vertically up the back of the apex of the petrous temporal. Having arrived at the sharp upper border of this bone, it bends forwards, under the petro-sphenoidal ligament of Gruber, practically at a right angle to run almost horizontally forwards in the cavernous sinus.

Here it is placed to the outer side of the carotid artery to which it is held by communications from the sympathetic plexus (see Fig.).

Now if we consider a tumour in any position in the cranium there will come a time when owing to the increase in the intracranial pressure the brain will be forced to its largest outlet, the foramen magnum, and foraminal herniation ensue. As a result of this the medulla and the pons will tend to move downwards.

Now the sixth nerve is fixed to the pons and more or less held in the cavernous sinus. It will therefore be pressed against the sharp upper border of the petrous temporal with resulting interruption of conduction and palsy of the external rectus.

Blows on the vault of the skull, quite apart from those which are complicated by basal fractures involving the apex of the petrous temporal will İ think also tend to force the hind-brain downwards with resulting tension on the sixth nerve. A similar condition of movement towards the foramen magnum will follow compression of the skull in a difficult labour with or without forceps and explain the sixth nerve birth palsy.

\section{BIBLIOGRAPHY}

1. Uhthoff.-Trans. Ophthal. Soc. U.K., Vol. XXXIV, p. 70, 1914.

2. Collier, James.- " The false localizing signs of intracranial tumour." Brain, Vol. XXVII, p. 490, 1904

3. Cushing, Harvey..." Strangulation of the nervi abducentes by lateral branches of the basilar artery in case of brain tumours." Brain, Vol. XXXII, 1910-11.

4. Stopford, J. S. B. - "The arteries of the pons and medulla oblongata." Jl. Anat. and Phys., Vol. L, 1915-16, and Vol. LI, 1916-17. 